\title{
Ipsilaterally evoked responses of the zebra finch visual wulst are reduced during ontogeny
}

\author{
Manfred Bredenkötter and Hans-Joachim Bischof \\ Lehrstuhl fur Verhaltensphysiologie, Universität Bielefeld, Bielefeld (F.R.G)
}

(Accepted 16 January 1990)

Key words: Development; Bird's visual wulst; Ipsilaterally evoked potential; Contralaterally evoked potentral

\begin{abstract}
Visual wulst responses to ipsl- and contralateral visual stimuli were investigated in young zebra finches (Taeniopygta guttata castanotss Gould) of different ages. Contralateral responses in $20,40,60$ and 80 day old birds do not differ significantly from those in adults. In contrast, ipsilateral responses decrease substantially during development and become very weak and irregular in adult birds
\end{abstract}

The visual wulst, the telencephalic end station of the thalamofugal pathway, receives information from the ipsilateral eye by recrossing fibres from the thalamic nuclear complex (OPT) ${ }^{8,10,11,14}$. Pettigrew and Konishi ${ }^{13}$ were able to demonstrate that most neurons in the visual wulst of owls, birds with frontal eyes, are binocularly driven and are arranged in topographical order. In contrast, there is little evidence for processing of ipsilateral stimuli in laterally eyed birds, although a recrossing projection exists. Electrophysiological recordings in pigeons ${ }^{12}$, chicks $^{5,15}$ and zebra finches ${ }^{3}$ revealed that only a small portion of the visually responsive area of the wulst responds to ipsilateral stimuli, and that these responses are very irregular and weak. Therefore, a discrepancy exists between anatomical and physiological findings in laterally eyed birds: although a quite prominent recrossing pathway exists which could well process ipsilateral information, the responsiveness of the wulst to ipsilateral stimuli is low.

We found that ipsilateral processing can be enhanced by application of picrotoxin to the ipsi- and contralateral wulst in adult birds (Bredenkötter and Bischof, in preparation). We therefore wondered whether the lack of ipsilateral stimulus processing is due to suppression mechanisms which develop during ontogeny. To test this hypothesis we recorded visually evoked responses from the wulst of zebra finches at different ages.

The experiments were performed on 25 juvenile and adult zebra finches of different ages: $20(n=7), 40(n=$ $7), 60(n=3)$ and 80 days $(n=3)$, and adults ( $>100$ days, $n=5$ ). As the skull is not solid enough in birds younger than 20 days to allow reliable stereotaxic approaches, we did not record from birds of younger ages. The brain has reached its final size by 20 days of age (Herrmann, personal communication). This meant that we could use our stereotaxic atlas of the zebra finch brain (Nixdorf and Bischof, unpublished) for all ages. The position of maximum ipsilateral and contralateral amplitudes was determined in another study (Bredenkötter and Bischof, in preparation). In each bird several electrode tracks were made in an array including this position. The track with highest amplitudes and shortest latencies within the hyperstriatum accessorium (HA) was selected for further processing.

The birds were anaesthetized with $0.1 \mathrm{ml}$ urethane $(20 \% \mathrm{w} / \mathrm{v})$ and placed in a stereotaxic headholder ${ }^{1}$. Visually evoked potentials (VEPs) were recorded with glass micropipettes (10-20 M $\Omega$ ) filled with $0.5 \mathrm{M}$ sodium citrate. For each measurement, 64 stroboscope flashes (1 ms) were directed by fibre optics to the left or the right eye, with an interstimulus interval of $5 \mathrm{~s}$. The responses were recorded over a range of $500 \mathrm{~ms}$ and averaged by a signal averager (Nicolet-Instruments). The averaged signals were transferred to a HP 86B microcomputer, which also triggered the stimuli and controlled the experimental procedure. Amplitudes and latencies were estimated by a maximum-minimum routine of the computer. Additional information about latencies and amplitudes was evaluated by processing the evoked potential plots on a graphics tablet.

Our experiments show that the amplitudes of contralateral responses are already adult-like in 20 day old birds and do not change essentially at different ages. Fig. 1 shows representative examples of recordings from the

Correspondence H.J. Bıschof, Lehrstuhl für Verhaltensphysıologie, Universitat Bielefeld, Postfach 8640, D-4800 Bielefeld 1, F.R.G. 
contra
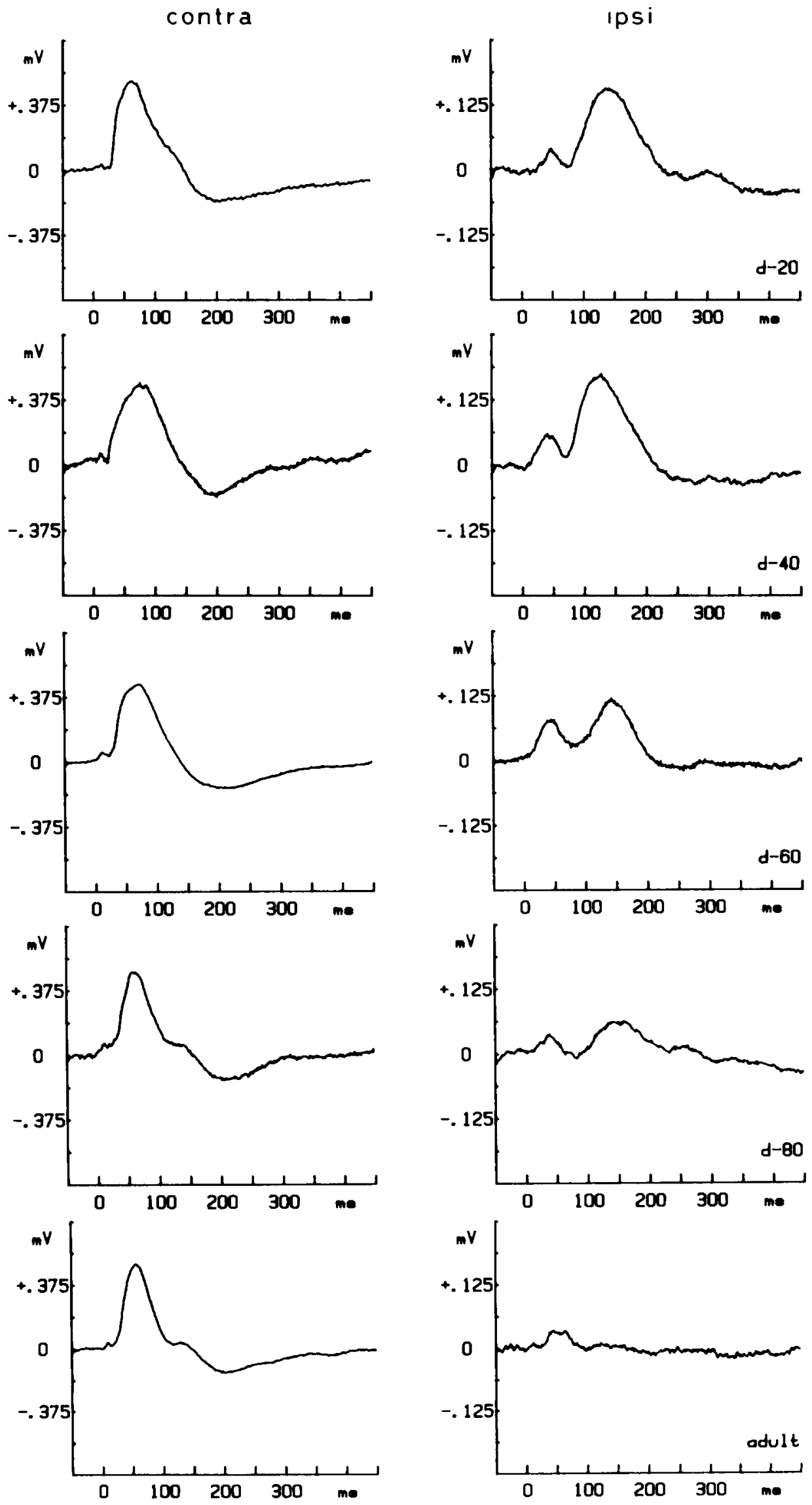


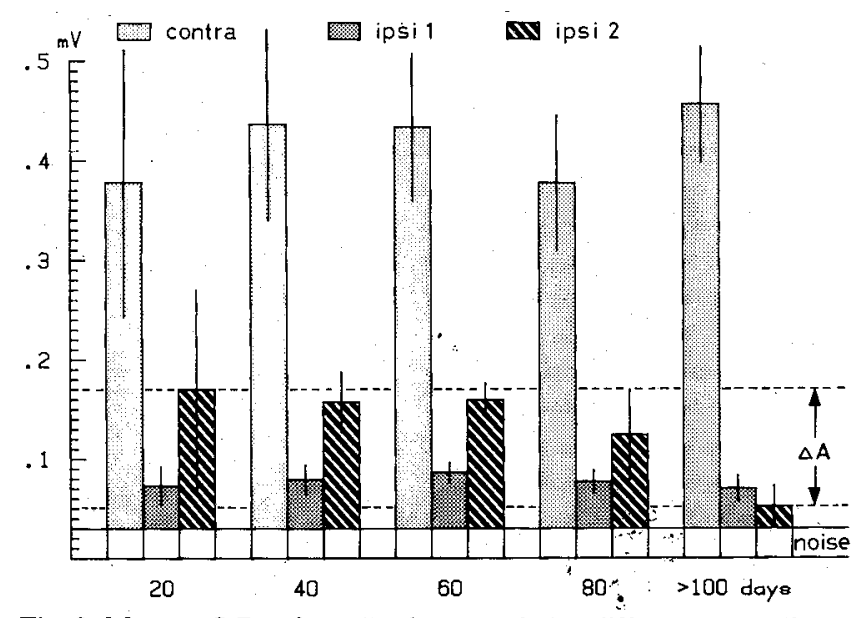

Fig. 2. Mean \pm S.D. of amplitudes recorded at different ages. There are no significant differences in the contralaterally evoked responses of juvenile and adult birds (Mann-Whitney $U$-test). Amplitudes of the second component of ipsilateral VEPs (striped bars) at days 20, 40,60 and 80 are significantly different from adults $(P<0.05)$. Contra, ipsi: stımulated eye, ıpsi 1. furst component of VEP, ipsi 2: second component of VEP.

hyperstriatum accessorium (HA) of birds of different ages. Contralateral responses are of high amplitude by day 20 (about $0.4 \mathrm{mV}$ ), and this amplitude does not change significantly with age (Fig. $2, U$-test: $P>0.05$ ). Peak latencies are at about 50-70 ms, first deflection after stimulation appears at about 20 to $25 \mathrm{~ms}$. During development, the positive peak becomes sharper, and a second portion with a latency of $120-130$ ms appears.

Compared to contralateral responses, ipsilaterally evoked potentials are smaller in all age groups (see different scalings in Fig. 1). In 20 day old birds, two positive peaks of different latency and amplitude can be detected. The first small component comprises a latency of about $50 \mathrm{~ms}$ and an amplitude of $0.04-0.07 \mathrm{mV}$. This peak does not change significantly during ontogeny (Fig. 2). In contrast, the amplitude of the second peak (latency $120-150 \mathrm{~ms}$ ) is high in 20 day old birds and decreases constantly with age. In adult birds the mean amplitude of the second peak decreases to $0.05 \mathrm{mV}$ and is very difficult to differentiate from the background noise $(0.03 \mathrm{mV})$. The difference in amplitude $(\triangle \mathrm{A})$ of the second peak is $0.12 \mathrm{mV}$ between 20 day old and adult birds (Fig. 2). This difference is significant ( $P<0.025, U$-test), as well as the differences for all other age groups when compared with adults $(P<0.05)$.

The early component, which does not show any statistically significant differences between the age groups, becomes more irregular in older birds, i.e., it cannot be recorded as constantly as in younger birds.

Our results clearly show that the reactions of the visual wulst to ipsilateral visual stimuli decrease with increasing age. The two components of the potential which can be measured within the hyperstriatum accessorium are affected to a different degree. Whereas the first peak remains at the same amplitude and the effect of age is of a more unpredictable response pattern (which cannot be shown here), the amplitude of the second peak decreases between 20 and $>100$ days (Figs. 1, 2). We will demonstrate in another study (Bredenkötter and Bischof, in preparation) that this second peak can be detected in adult birds which had received a picrotoxin application to the contralateral wulst. This portion of the evoked response is probably not mediated by the recrossing route from the OPT to the contralateral wulst, but comes from the wulst of the contralateral hemisphere. Evidence from zebra finches ${ }^{11}$ and from pigeons ${ }^{4}$ indicates that a projection exists between the two wulst areas via the hippocampus.

Given that access to ipsilateral stimuli is necessary for binocular processing of visual information, our results indicate that the visual wulst loses at least some of its capability for binocular visual processing during ontogeny. As laterally eyed birds perform well in binocular tasks $^{2,9}$ it is possible that this task has been transferred to another visual system. Indeed, within the ectostriatum, the end station of the tectofugal system, the capability to respond to ipsilateral stimuli improves during ontogeny ${ }^{7}$.

Given the shift of responsiveness to ipsilateral stimuli between thalamo- and tectofugal pathways, our results may have some impact on evolutionary considerations. As it is not likely that binocular processing by the thalamofugal system is a 'primitive' form of visual processing (owls are birds of rather high evolutionary state), it seems likely that binocular processing was possible in both visual systems in primitive birds, and that both pathways were independently selected for specialized visual processing in different species. To prove this, more comparative research needs to be performed on primitive birds and on reptiles.

Our thanks are due to Mrs. Edda Geissler for her assistance in preparnng the figures and Dr. Nicky Clayton for improving the English Supported by the Deutsche Forschungsgemeinschaft (Bi 245/4)

Fig. 1. Visual wulst recordings of ipsi- and contralateral VEPs in juvenıle and adult birds. Contralaterally evoked responses (left side) of juvenule birds do not differ essentially from those of adult birds. Ipsilaterally evoked responses (nght side) consist of two different components: a small first one and a large second one. The latter decreases durıng development and is not detectable in adult bırds. Contra, ıpsi: stimulated eye; stımulus at $0 \mathrm{~ms}$; average $64 \times$ 
1 Bischof, H.J., A stereotaxic headholder for small birds, Brain Res Bull., 7 (1981) 435-436.

2 Bischof, H.J., The visual field and visually guided behavior in the zebra finch, $J$ Comp. Physiol. A, 163 (1988) 329-337.

3 Bredenkötter, M. and Bıschof, H.J., Visually evoked potentials in the visual wulst of zebra finches. In N. Elsner and F Barth (Eds.), Sense Organs. Interfaces Between Environment and Behaviour, Thieme, Stuttgart, 1988, p. 256.

4 Casini, G., Bingman, V.P. and Bagnol, P, Connections of the pigeon dorsomedial forebrain studied with WGA-HRP and ${ }^{3}$ H-proline, J Comp. Neurol., 245 (1986) 454-470

5 Denton, C.J , Topography of the hyperstriatal visual projection area in the young domestic chicken, Exp. Neurol, 74 (1981) 482-498.

6 Engelage, J. and Bischof, H.J., Enucleation enhances ipsilateral flash evoked responses in the ectrostriatum of the zebra finch (Taeniopygia guttata castanotis Gould), Exp. Brain Res., 70 (1988) 79-89.

7 Engelage, J. and Bischof, H.J., Development of flash evoked responses in the ectostriatum of the zebra finch: an evoked potential and current source-density analysis, Exp. Brain Res., in press.

8 Karten, H.J., Hodos, W., Nauta, W.J.H. and Revzin, A M.,
Neuronal connections of the 'visual wulst' of the avian telencephalon. Experimental studies in the pigeon and owl, J. Comp Neurol., 150 (1973) 253-278

9 Martinoya, C., Le Houezec, J and Bloch, S., Depth resolution in the pigeon, J Comp Physiol. A, 163 (1988) 33-42.

10 Meier, R.E., Mihailovic, J. and Cuenod, M., Thalamic organization of the retino-thalamo-hyperstriatal pathway in the pigeon, Exp. Brain Res, 19 (1974) 351-364.

11 Nixdorf, B.E and Bischof, H.J., Afferent connections of the ectostriatum and visual wulst in the zebra finch - a HRP study, Brain Research, 248 (1982) 9-17

12 Perisic, M., Mihailovic, J. and Cuenod, M, Electrophysıology of contralateral and ipsilateral visual projections to the wulst in pigeon (Columba livia), J. Neuroscl., 2 (1971) 7-14

13 Pettigrew, J.D. and Konishi, M., Neurons selective for onentation and binocular disparity in the visual wulst of the barn owl, Sclence, 193 (1976) 675-678.

14 Powell, T.P S. and Cowan, W M , The thalamic projection upon the telencephalon in the pigeon, J. Anat., 95 (1961) 78-109.

15 Wilson, $P$., The organization of the visual hyperstriatum in the domestic chick. II. Receptive field properties of single units, Brain Research, 188 (1980) 333-345 